\title{
REVISITANDO O PLURALISMO JURÍDICO NA AMÉRICA LATINA: PARA UM PENSAMENTO JURÍDICO CRÍTICO NO DIREITO
}

\author{
${ }^{1}$ Lucas Machado Fagundes \\ ${ }^{2}$ Antonio Carlos Wolkmer
}

\begin{abstract}
RESUMO
O estudo explora o pensamento jurídico crítico por meio das expectativas do pluralismo jurídico no contexto regional. Analisam-se as principais manifestações teóricas que pensam o direito como um fenômeno originado das manifestações sociais. A metodologia utilizada foi a pesquisa bibliográfica, valendo-se de procedimentos analíticos e histórico-estruturais. Apresenta-se uma elaboração que tem como resultado a possibilidade de pensar outras formas de direito com uma matriz teórica original, bem como o compromisso de fomentar a emergência das práticas comunitárias produzidas como ausentes, as quais intentam um processo político amplo de luta pela reinvenção do Direito como forma de emancipação social.
\end{abstract}

Palavras-chave: Pluralismo jurídico, Direito crítico, América latina

\section{REVISANDO EL PLURALISMO JURÍDICO EN AMÉRICA LATINA: PARA UN PENSAMIENTO JURÍDICO CRÍTICO EN EL DERECHO}

\section{RESUMEN}

El estudio explora el pensamiento jurídico crítico a través de las expectativas del pluralismo jurídico en el contexto regional. Analizan las principales manifestaciones teóricas piensan el derecho como un fenómeno originado de las manifestaciones sociales. La metodología utilizada fue la investigación bibliográfica, haciendo uso de procedimientos analíticos e histórico-estructurales. Presenta como resultado la capacidad de pensar en otras formas de Derecho con una matriz teórica original, y compromiso de fomentar la emergencia de prácticas comunitarias producidas como ausentes, que tengan la intención de un amplio proceso político de lucha por la reinvención derecho como forma de emancipación social.

Palabras-claves: Pluralismo jurídico, Derecho crítico, América latina

\footnotetext{
1 Doutor em Direito pela Universidade Federal de Santa Catarina - UFSC, Santa Catarina. (Brasil). Professor da Universidade do Extremo Sul Catarinense - UNESC, Santa Catarina. (Brasil). E-mail: lucas-sul@ hotmail.com

2 Doutor em Direito pela Universidade Federal de Santa Catarina - UFSC, Santa Catarina. (Brasil). Professor da Universidade Federal de Santa Catarina - UFSC, Santa Catarina. (Brasil). E-mail: acwolkmer@ gmail.com
} 


\section{INTRODUÇÃO}

A discussão ora inaugurada estabelece que o espaço-tempo das elaborações teóricas que vem ganhando força encontra-se na realidade periférica ou marginal do continente latinoamericano, em que todas as ponderações dos autores e teorias selecionadas estão diretamente ligadas as manifestações ocorridas na região. Logo, vale ressaltar que a escolha de alguns autores e a ausência de outros, cumpre um recorte expositivo para abrir-se o panorama generalizado, traduzindo aqui significativas vertentes em países como Argentina, Brasil, Colômbia e México, porém sem esquecer que atualmente os demais países latino-americanos também já contam com importantes divulgadores e teorizadores que tem no Pluralismo Jurídico seu núcleo referencial principal (Peru, Equador, Bolívia e América Central).

Diante disso, na sequência, o trabalho recebe a contribuição dos pensadores latinoamericanos que verificam seus estudos fora da realidade brasileira, como o caso de Carlos Cárcova na Argentina, Oscar Correas e Jesús Antonio De la Torre Rangel no México, do Instituto Latino-Americano de Servicios Legales - ILSA, na Colômbia, fontes germinadoras de um pluralismo jurídico na América Latina.

Estes aportes teóricos farão abertura para a contribuição do pluralismo jurídico comunitário-participativo, que será explorado nos seus pilares de fundamentação como maneira de concluir esse apanhado exploratório de algumas das principais vertentes teóricas do fenômeno social do pluralismo jurídico no Brasil e na América Latina nas últimas décadas.

\section{CONCEPÇOES CONTEMPORÂNEAS DE PLURALISMO NO DIREITO DESDE AMÉRICA LATINA}

Nesta perspectiva, trabalhar-se-á a partir de uma importante obra de teoria crítica do direito, de autoria do jusfilósofo da Universidade de Buenos Aires, Carlos Maria Cárcova e suas idéais expressadas sobre o pluralismo jurídico. Parte-se do seu livro intitulado $A$ opacidade do direito, publicado no Brasil em 1998 pela Editora LTR no qual, em tópico específico irá abordar o pluralismo jurídico partindo da leitura de Jean Carbonnier, destacando o fator da anomia e da aculturação, travados nos ordenamentos em conflito e a crise do monismo jurídico. $\mathrm{O}$ autor refaz uma importante jornada construtiva do pluralismo na história, partindo da primeira metade do século XX com os estudos de Ehrlich e alcançando a obra fundante da pesquisa na América Latina, conhecido como $O$ direito de passárgada de $\mathrm{B}$. S. Santos; e concluindo mencionar os encontros de direito alternativo em Florianópolis, Santa Catarina, com enfoque especial na obra de Antonio C. Wolkmer e seu pluralismo jurídico 
comunitário- participativo.

Sendo assim, aborda pontualmente três aspectos na temática do pluralismo jurídico, primeiramente ligada as questões da aculturação, apresentando a problemática pertinente à América Latina, excepcionando os países do Rio da Prata (Uruguai e Argentina), em que o sentido de existência da cultura ancestral e/ou autóctone estão impregnados no imaginário legal social, o qual segundo o autor:

Em termos gerais, na América Latina, talvez como exceção quase solitária dos países do Rio da Prata, apresentam-se situações complexas envolvidas na sobrevivência de regimes legais ancestrais ou tradicionais, que não só mantêm uma relativa eficácia, paralelamente ao direito estatal, mas em determinados grupos ou em certas regiões possuem uma força vinculante ainda, superior, que comporta a abrogação desse direito estatal. (CÁRCOVA, 1998, p. 73)

Admite na presente etapa do trabalho a problemática de jurisdição quanto a aplicabilidade do direito indígena em contraponto a juridicidade do direito estatal, mencionando duas instituições tradicionais ameríndias que estariam em confronto com o ordenamento da sociedade moderna, tematizando com mais detalhe o casamento a prueba (servinakuy), traz o autor que:

O certo é que quando alguns membros dessas comunidades as abandonavam para migrar para as periferias urbanas em busca de melhores condições de vida - nunca alcançadas, certamente prematuros deixavam de ser um costume ancestral, regido por normas tradicionais. Tranformavam-se nos meios receptores, em delitos severamente castigados em muitos casos. (...) O que anteriormente representava o cumprimento de um mandato biológico-cultural passava a significar um delito aberrante. O direito do qual o indígena era portador transformava-se num contradireito para a lei do Estado. (CÁRCOVA, 1998, p. 75)

Entretanto, como não faz parte aqui elaborar especificamente a solução tratada pelo autor ao caso, cumpre apenas enunciar que tal se passou a construir pela eficiente elaboração teórica no campo do direito penal pelo jurista Eugénio Raul Zaffaroni, em que sua obra penalística tratou de dar uma dinâmica diferenciada ao tratamento da lógica estatal excludente e rígida, de acordo com Cárcova,

\begin{abstract}
O fato de Zaffaroni não mencionar o tema específico do pluralismo e de que sua explicação implica uma construção dogmática muito elaborada, que permite atender ao problema da diversidade cultural e á coexistência de diversos ordenamentos, da perspectiva do direito predominante, isto é, do direito estatal, não diminui a pertinência de sua argumentação. (CÁRCOVA, 1998, p. 79)
\end{abstract}

É justamente problematizando no campo teoria do direito, mas com profundas marcas da sociologia e da antropologia jurídica que Cárcova irá introduzir o debate do pluralismo jurídico, avançado sobre a discussão das perspectivas da migração, multiculturalismo $e$ pluralismo, passando, após a explorar a partir do movimento brasileiro de direito alternativo, os estudos e debates sobre pluralismo, emancipação e direito alternativo, expondo o diálogo 
controverso e problematizador dos autores brasileiros durante os congressos de jurídicidade alternativa na década de 1990.

Sem esquecer que Cárcova, na exposição da sua teoria parte indubitavelmente da pesquisa de B. S. Santos nas favelas do Rio de Janeiro, culminando no pluralismo jurídico wolkmeriano e a crítica que este recebe dos teóricos do direito como Luciano de Oliveira, Eliane Junqueira, Marcelo Neves e Edmundo de Arruda Lima Jr.

Aponta o jusfilósofo "portenho", que a questão do debate em torno do pluralismo jurídico, longe de ser uma sistêmica elaboração teórica, é muito mais um desajustado encontro de controvérsias e polêmicas em torno da perspectiva de direito. Interpreta o autor que tal posicionamento dos pesquisadores irá incorrer num reducionismo do tema, ou seja:

\begin{abstract}
Os sentidos e as distinções do discurso sobre o pluralismo jurídico, como ficou exposto, são muito diversos. Em geral, essa diversidade obedece duas razões, uma mais evidente do que a outra. A mais evidente é a que os autores têm interesses distintos e se preocupam em enfatizar aspectos particulares de uma problemática mais ampla, com certa indiferença com relação a outros que, de fato, também estão nela incluídos e para os quais deveria ser mantido um mínimo de coerência. (...) A menos evidente dessas razões, embora sem dúvida a mais importante, é que não há coerência sobre como conceber o direito, como defini-lo, pelo menos de um ponto de vista operativo. É comum então que furiosos críticos do positivismo só relevem as dimensões normativas do fenômeno jurídico, incorrendo no mesmo redutivismo que criticam. (CÁRCOVA, 1998, p. 111)
\end{abstract}

Encontra-se na obra do autor uma forte impregnação do ordenamento oficial de forma hegemônica, basta verificar de sua noção do direito, ligado exclusivamente a uma teoria pura da normatividade oficial, veja-se:

\footnotetext{
Observa-se uma forte tendência nos autores do pluralismo de equiparar regras morais ou religiosas, costumes e rituais atávicos com normas jurídicas. Isso se deve, conforme cremos, a uma ênfase desproporcionada em suas críticas ao formalismo jurídico. No afã de manejar uma noção de direito não redutiva acabam destruindo-a. (CÁRCOVA, 1998, p. 119)
}

Na perspectiva do professor de Filosofia do Direito da UBA, suas percepções sobre o direito pouco teriam de rompimento com a ordem jurídica posta, extraindo-se muito mais perspectivas de reforma e mudança do que propriamente transformação. Acredita Cárcova que se possa realizar tarefas emancipatórias a partir do próprio espaço do direito hegemônico, sem, entretanto, desconstruir suas armadilhas formais, pois assim,

Em face das teses que reivindicam um pluralismo alternativo na medida em que confronta e exclui o direito oficial e o papel do Estado, preferimos imaginar o alternativo como uma complexa operação a partir da qual se desenvolvem os valores emancipatórios contidos nas promessas não cumpridas da modernidade, reivindicando o direito como paradoxo e não como pura negatividade; como situação estratégica, foucaultianamente dizendo, e não como simples instrumento de opressão. O direito, para nós, é ao mesmo tempo opressão e emancipação. (CÁRCOVA, 1998, p. 121) 
Não se pode omitir que realmente o direito se efetiva na esfera da opressão e da emancipação, num movimento dialético de contradição e superação. Entretanto, é justamente esta segunda parte do movimento (emancipação) em que as teorias tradicionais do direito resistem em tornar fático, porém entende-se no âmbito da pesquisa, em que a América Latina encontra-se num processo avançado de transformação das instituições políticas e jurídicas e que o grau de contradição ocasionou a insurgência de uma efervescência de superação das contradições opressoras da nossa história periférica. Consequentemente, aos poucos irá se evidenciando a superação da contradição antes citada.

Percorrido brevemente o trajeto através do representante da crítica jurídica na Argentina e sua exposição sobre pluralismo jurídico, cumpre, indubitavelmente demonstrar as considerações da escola mexicana, e por consequência possuidor de um plural campo de juridicidade, muitas delas ligadas às comunidades indígenas históricas.

No âmbito da análise, compete expor o pensamento de dois pesquisadores e precursores do pensamento pluralista no referido país, trata-se das obras de Oscar Correas, professor e investigador acadêmico da Universidade Nacional Autônoma do México - UNAM e Jesús de la Torre Rangel, advogado popular e professor em Aguascalientes, ambos com vertentes de pensamento diferentes, mas aproximados quando o assunto chama-se pluralismo jurídico.

Diante disso, vale começar pelo marxista e kelseniano ${ }^{l}$, se é que é possível entender essa contradição, Oscar Correas a partir da sua forte formação marxista e sua profunda leitura e conhecimento crítico em relação à obra de Hans Kelsen, trabalha uma dura e contundente crítica ao direito moderno e aos efeitos do neoliberalismo no direito. Correas desenvolveu a partir da Revista Crítica Jurídica e de seu grupo de investigadores trabalhos relacionados aos temas, Direito e Marxismo, Pluralismo Jurídico ${ }^{2}$, Direito Indígena ${ }^{3}$ e Justiça Comunitária.

Entretanto, interessa aqui suas posições referentes ao objeto de estudo em pauta, logo, sua obra Introducción a la Sociología Jurídica, do ano de 1994, em que encontra um capítulo específico para tratar o tema do pluralismo jurídico. Assim, suas observações partem obviamente da construção kelseniana do direito, em que a partir de perguntas simples e respostas diretas, constrói toda idéia de justificação da ordem jurídica tradicional, problematizando a questão da ficção jurídica da norma fundante ou Grundnorm e a problemática de um único centro gerador dessas normas.

\footnotetext{
${ }^{1}$ Autodenominação proferida no Seminário Direito e Neoliberalismo, ocorrido entre os dias 24,25 e 26 de outubro de 2011, em Florianópolis, Santa Catarina, Brasil.

${ }^{2}$ Ver a este respeito a obra organizada pelo autor, intitulada Pluralismo Jurídico: otros horizontes. Ediciones Coyocán: DF, México. 2007.

${ }^{3}$ CORREAS, Oscar (coord.), Derecho indígena mexicano, I e II. Ediciones Coyocán: DF, México. 2009.
} 
Tal relação localiza-se no âmbito de delimitar o que se chama jurídico em um ordenamento ou comunidade, logo, a primeira definição descrita pelo autor é referente ao que se trata sistema jurídico, e no âmbito da sociologia jurídica como se pode trabalhar com este conceito nas comunidades. Para Correas (...) un sistema jurídico pueda ser definido como un conjunto de normas organizadas por una norma fundante o regla de conocimiento. (1994, p. 102) Ou seja,

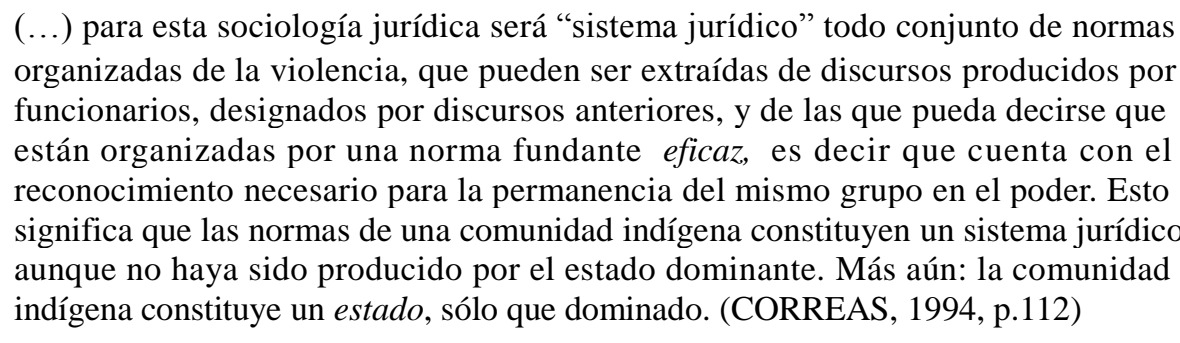

Constatada esta situação fática, resta ao autor especificar a teoria do pluralismo jurídico, o qual entende como (...) la coexistência, en un mismo território, de dos o más sistemas jurídicos; es decir, de normas que se organizan alredor de distintas reglas de reconocimiento. (CORREAS, 1994) Vale identificar as diversas manifestações que se encontram no espaço-tempo do país que habita, o México, através das comunidades indígenas, organizações guerrilheiras, empresas privadas etecétera.

Diante disso, surgem segundo o autor, outro problema do âmbito de definição do que se conclui como pluralismo jurídico, para isto reformula o conceito acima e refere que,

Definiremos pluralismo jurídico como la coexistência en el tiempo y en el mismo
território, de dos o más sistema normativas eficaces. De "sistema" ya tenemos un
concepto - organización alredor de una norma de reconocimiento o fundante - y de
"normativo" también: discurso prescriptivo autorizado que organiza las sanciones y
reconocido o eficaz. (CORREAS, 1994, p. 114)

Assim, reconhece o autor que este conceito é limitado e que através da pesquisa empírica poderá ser atualizado, bem como, somente a mesma pesquisa pode definir se um sistema é ou se define como pluralismo jurídico, ora, atribui muito mais a sociologia jurídica esta tarefa do que propriamente a teoria do direito. Isto é importante no âmbito deste trabalho, na medida em que se verá, quanto às críticas ao pluralismo jurídico, o reducionismo as manifestações criminosas como formas específicas de um direito alternativo, situando tais manifestações, aos quais se deve repudiar, como um sistema normativo igual aos sistemas normativos que promovem emancipação.

Dentro da elaboração do autor, importa sua relevante exposição sobre sistema jurídico subversivo, denominação atribuída segundo o mesmo, 
(...) llamaremos "sistemas jurídicos subversivos" a aquellos sistemas alternativos cuya eficácia consistiria em la supresión del sistema jurídico actual dominante. Esta definición incluye las de pluralismo jurídico y la de sistema jurídico alternativo. Pero le agregamos la idea de que la eficacia del sistema subserviso acarrería el derrumbe del sistema al que combate, y por lo tanto el derrocamiento de su grupo en el poder. (CORREAS, 1994, p. 118)

Infere-se desta categoria na medida em que os sistemas jurídicos periféricos estão não somente em contraposição, convergências ou concorrência com o ordenamento oficial, como também em algumas situações intentam a transformação da ordem normativa, abrindo o fechado aparato estatal para um campo amplo e complexo de manifestações normativas, assim é que vem se manifestando atualmente os sistemas jurídicos nos países andinos (tendencias do chamado ,novo ${ }^{\text {ee }}$ constitucionalismo latino-americano).

Por último, refere o autor que nem toda a ordem normativa se convenciona jurídica, criando delimitações com as quais se reduz o campo de verificação do pluralismo jurídico. Ainda que se venha discordar do posicionamento do autor, que parte da idéia de jurídico embasada nas concepções com as quais constrói sua crítica (matriz kelseniana), afirma-se que as manifestações de organizações populares e das organizações empresariais comporiam este rol de ordenamentos normativos plurais que deveriam verificar-se a juridicidade de sua formulação, aplicação e principalmente eficácia, novamente atribuindo tal tarefa a investigação da sociologia jurídica.

Outro autor mexicano que se destaca na divulgação e exploração da temática do pluralismo jurídico, é Jesus de la Torre Rangel ${ }^{4}$, com diversos estudos publicados relacionados aos povos campesinos e indígenas, oprimidos e expoliados na América Latina.

Este autor, através da sua experiência como advogado popular no México, exprime as pretensões de um uso do direito como arma de libertação destas comunidades marginalizadas e sofredoras com as incursões patrimonialistas do uso hegemônico do direito moderno. Com este título, O Direito como arma de libertação na América Latina, o professor destaca que é possível alcançar justiça através da arquitetura jurídica de perverter a lógica da normatividade tradicional em favor dos setores que mais necessitam de proteção. Rompendo assim, a lógica racionalista do positivismo jurídico e da interpretação conforme o conteúdo formal da normatividade estatal. Dirá o autor quanto ao direito como arma de libertação:

\footnotetext{
${ }^{4}$ Ver mais detalhes em: WOLKMER, Antonio Carlos. Pluralismo Jurídico: Fundamentos de uma nova cultura do direito.4ed. São Paulo: Editora Saraiva, 2015, p. 224-227.
} 


\begin{abstract}
En ese texto sostenemos que, a pesar de que la normatividad objetiva producida en los Estados expresa la legalidad de la injusticia, el Derecho, la juridicidad, sirve también para hacer justicia; y que la búsqueda de esa justicia, implica procesos sociales de liberación. Por eso decimos que el Derecho puede ser un instrumento, una herramienta, un arma de liberación, tanto como uso alternativo del Derecho, como pluralismo jurídico. (TORRE RANGEL, 2010, p. 4)
\end{abstract}

Compreende Torre Rangel, que a legalidade oficial normatiza a injustiça social, e fundamenta sua análise na dissonância entre o normativado e o realmente verificado na realidade social das comunidades indígenas e campesinas do México, atribuindo inclusive exemplificativamente à insurgência do Exército Zapatista de Libertação Nacional (EZNL), movimento social na região de Chiapas, México, um fator da constatação de que o direito oficial não protege e nem garante condições humanas e dignas de vivências, quiçá, legitima atrocidades e prioridades de determinados setores (dominantes). Y esta realidad injusta se arropa, se reviste de legalidad; es la legalidad de la injusticia; en otras palabras, la normatividad que producen y rigen los Estados, y que regula los intercambio internacionales, frecuentemente legalizan lo injusto y la violación de los derechos humanos. (TORRE RANGEL, 2010, p. 57)

Nessa senda, importa saber do autor o que este entende por direito, na medida em que denuncia a normatividade legalista do direito oficial, mas também acredita que o seu uso poderá contornar as situações calamitosas das comunidades oprimidas, e tão logo oferece que:

\footnotetext{
Reconocemos que el Derecho es Ley, conjunto de normas, pero no sólo es eso, constituyen también derechos subjetivos, facultades de las personas y los grupos sociales sobre lo suyo, y además, Derecho es las cosas y/o conductas debidas a los otros, esto es lo justo objetivo, como concretización de la justicia. Por otro lado, el Estado no es la única fuente de producción de lo jurídico. Los usos y costumbres, los principios generales del Derecho, la realidad misma, naturaleza e historia, del ser humano y de las cosas, produce juridicidad. El Derecho nace del pueblo; de las relaciones interhumanas, de las luchas y reivindicaciones de diversos colectivos. (TORRE RANGEL, 2010, p. 58)
}

E complementa referindo que (...) En varios de mis escritos, he dicho que el ser humano es la raíz de todo Derecho, la fuente primigenia de toda juridicidad; y, por lo tanto, de algún modo, los derechos humanos son necesidades juridificadas. (TORRE RANGEL, 2010, p. 59) E, é justamente nessa necessidade humana justificada que se encontra a base da filosofia de Torre Rangel, na medida em que se embasa no chamado iusnaturalismo histórico ou ultimamente buscando nas fontes da filosofia da libertação dusseliana, em especial emprestado seu método analético, produz o iusnaturalismo histórico analógico. Veja-se o que ele descreve como a primeira categoria: 
Por lo que La concepción filosófica desde la cual se ha abordado el Derecho, a lo largo de este trabajo, es el iusnaturalismo histórico. Iusnaturalismo porque consideramos que lo prioritario en lo jurídico está constituido por la justicia, el bién común, y los derechos humanos. Pero la realidad social que se nos presenta, frecuentemente contraría la justicia, el bien común y los derechos humanos postulados; la realidad histórica, en la que estamos inmersos, la encontramos produciendo injusticia, mal común y violación sistemática de los derechos. (TORRE RANGEL, 2010, p. 57)

Logo se pergunta, mas porque utilizar a categoria iusnaturalismo histórico, e Torre Rangel, trata de justificar,

Iusnaturalismo histórico, porque no debemos conformarnos con La reflexión teórica acerca de la esencia del ser humano, de sus derechos y de la justicia en sus relaciones; sino que debemos de tener en cuenta la realidad histórica que niega la vigencia de los derechos humanos, de la justicia y del bien común, pero también, es en la propia realidad histórica, en donde tiene sentido aquello que se afirma como justicia, derechos y bien común, ya que la historia es el lugar de su concreción. (2010, p. 57)

No tocante a segunda categoria, mais complexa que a primeira, compreende o entendimento do direito como conhecimento análogo, a partir do referencial teórico de Efraín Gonzáles Morfin,

\begin{abstract}
Assim, o direito é um termo que se qualifica em forma análoga de várias realidades: a normatividade ou direito objetivo, a faculdade ou direito subjetivo, o justo objetivo como conduta ou coisa que se deve a outro e a ciência do direito. É necessário saber qual é o "analogado" principal em ordem de natureza, ou seja, aquela realidade jurídica onde se dá, propriamente, a essência do direito e que realmente influi nos "analogados" secundários. (TORRE RANGEL, 2004, p. 318)
\end{abstract}

Compreende que (...) norma, faculdad, justicia e ciencia jurídica son, análogamente, Derecho (TORRE RANGE, 1986, p. 12). Como já referido, toma emprestado da filosofia da libertação a metodologia analética de Enrique Dussel, finalizando a sua categoria de investigação do direito, teorizada no último livro lançado em 2011 ( Editora Porrúa, México), intitulado Iusnaturalismo histórico analético, obra na qual intenta expressar a última versão de sua filosofia e hermenêutica do fenômeno jurídico,

Intentamos, entonces, con una racionalidad analógica abordar lo jurídico de una manera integral. Aplicamos la analogía en el conocimiento, y en la comprensión del ser del Derecho; con la analéctica como método, proponemos un iusnaturalismo histórico; y para la interpretación jurídica recurrimos a la herméneutica analógica. De ahí nuestra propuesta de un iusnaturalismo histórico analógico. (TORRE RANGEL, 2011, p. X)

Dessas compreensões, o autor entende que a fonte geradora do direito, não é de forma alguma apenas o Estado, apesar de que como já foi referido, pode-se utilizar alternativamente o direito oficial para fins justos. Assim, introduz na realidade social as idéias do pluralismo jurídico, diante de uma concepção do direito que nasce do povo e tal situação se dá a partir da 
criatividade necessária desenvolvida pelas comunidades camponesas ou indígenas em produzir normas para satisfação de suas necessidades fundamentais, ou então, da situação fática de exigibilidade dos seus direitos humanos, ainda que contra o direito estatal normatizado (via de regra em benefício dos setores dominantes e dentro da concepção homogeneizadora da modernidade) que esfacelou a diversidade cultural e minimizou as culturas das comunidades a relações individuais na sociedade de privilégios econômicos, propriedade privada e individualismo. Entende que,

[...] el Derecho que nace del pueblo en esa riqueza analógica del término. En los ensayos que componen este libro nos encontramos con normas jurídicas que el proprio pueblo crea para regular sus relaciones y como defensa de sus causas justas y además el uso que hace de las normas vigentes; también, en otros lugares, encontramos la defensa que hace el proprio pueblo de los derechos subjetivos que se tiene como personas individuales o comunitariamente, en ocasiones reconocidos por el Derecho vigente y en otras negados per intuidos como naturales al hombre y a la comunidad: por todos los ensayos corre la vena de la búsqueda de justicia, el clamor de acceder a lo que les pertenece, a lo que es suyo; y por último, también, la práctica jurídico-política del pueblo, de vetas riquíssimas de reflexión para la elaboración de una nueva teoría del Derecho, o cuando menos, cuestiona para hacer replanteamientos de las ya existentes. (TORRE RANGEL, 1986, p. 12)

No âmbito da sua idéia de pluralismo jurídico, Torre Rangel, afirma que o fundamento da juridicidade esta dentro de outra perspectiva filosófica, além da mentalidade normativa do Estado, que o entendimento parte para outra idéia de direito, forjada em instâncias diversas que a tradicionalmente operada para o conceito. Aponta que a situação de miserabilidade e pressão sofrida pelas populações indígenas (exemplifica como EZLN) gera uma insurgência ao direito oficial e a criação de sua própria normatividade, ou seja, oriundo da (...) ausência de todo exercício real e eficaz dos direitos humanos básicos e elementares, a impraticabilidade da justiça e a total ineficácia de nossa normatividade (...) (TORRE RANGEL, 2004, p. 313)

Situa que o fenômeno jurídico é uma manifestação social complexa, e pode-se afirmar imersa em relações sociais também complexas e multifacetadas, dentro de um processo histórico conturbado e uma ordem econômica injusta, privatista e individualizante. Essas manifestações complexas são resultado das necessidades de sobrevivência que perpassam os sujeitos sociais, segundo Torre Rangel (2004) estas necessidades ganham força jurídica no momento em que se transformam em exigibilidade e a busca de satisfação das mesmas se materializa em processos políticos e exigência. Segundo o professor mexicano:

Da perspectiva dos direitos subjetivos - dos direitos humanos expressados como necessidades, como reclamos, como demandas - é questionado o sistema social, o político e o econômico. E é dessa forma que o mundo jurídico é sacudido em sua integridade, pela provocação à justiça que fazem as comunidades pobres. $\mathrm{O}$ começo do pluralismo jurídico funda-se - radica-se - na exigência de direitos. (TORRE RANGEL, 2004, p. 314) 
Importa lembrar, que tal situação se dá devido ao processo histórico de desumanização passado por estas populações que foram jogadas nessas condições ao longo da história. Diante disso, como se percebe nas experiências de insurgência de outras formas de justiça que trazem também a revelação de diversas maneiras de perceber a vida ou utilizando-se do termo da antropologia, cosmovisão diferente da vida, da sociedade, do comum, do direito, da filosofia encobertas no espaço geopolítico da modernidade pelos seus precursores e o modo de vida e cultura que se tornaram hegemônicos.

O que se passa com o direito quando se visualiza a pluralidade de ordens jurídicas é a efervescência do diferente irrompendo na realidade fática, o que traz não é nada novo, senão apenas desconhecido da história oficial e da ciência tradicional. O professor Torre Rangel salienta o significado de se observarem tais fenômenos, no sentido que,

[...] a importância do uso da juridicidade dos pobres constitui no fato de ele apresentar alternativas à lógica do Direito dominante, porque o desmistifica e revela um novo tipo de relações sociais. Implica o amadurecimento de certos setores da sociedade civil, que vão gestando uma rede de relações sociais, distintas à da formação social em vigor, de dominantes e dominados. (TORRE RANGEL, 2004, p. 317)

É justamente nesse ponto que relembra a categoria ética da alteridade, uma das perspectivas do pluralismo jurídico comunitário-participativo de Antonio C. Wolkmer.

Resta no âmbito do pluralismo jurídico na América Latina, lembrar a experiência colombiana do ILSA - Instituto Latinoamericano para una Sociedad y un derecho Alternativos. Que tem sua origem no ano de 1978, uma instituição não governamental com caráter civil, sem fins lucrativos, tendo sua sede na cidade de Bogotá DC, Colômbia, desenvolvendo atividades de pesquisa e ação política crítica do direito, que, além das manifestações de pluralismo jurídico, tem investigado direito alternativo e justiça popular na América Latina ${ }^{5}$.

Trata-se de um importante veículo de promoção crítica da prática e do estudo teórico do direito no continente, reunindo pesquisadores e operadores jurídicos comprometidos com uma idéia de transformação das condições sociais e econômicas, através de um movimento político, voltando-se os resultados das práticas e pesquisas para as realidades periféricas da América Latina, na medida em que o continente encontra-se como estratégico campo de lutas contra hegemônica. Assim, importa identificar o que são esses serviços legais alternativos,

\footnotetext{
${ }^{5}$ Verificar informações detalhadas na página eletrônica do instituto, disponível em http://ilsa.org.co:81/node/2.
} 
No es servicio jurídico alternativo el prestar asistencia legal individual a los pobres para que el abogado les resuelva sus problema personales. Es alternativo un servicio jurídico que se inscriba dentro de un gran proyecto de hacer que el pueblo sea sujeto de su historia, que haga las leyes para su provecho y las utilice para defender sus intereses. Dado que esto no es así porque estamos en una sociedad injusta, el ejercicio del derecho debe ir acompañado de la educación y la organización popular. Debe estar al servicio de los pobres organizados. Debe buscar, en último término una sociedad alternativa en donde realmente se ejerza el derecho para todos. Debe estar siempre vigilante para el hecho, de ser al mismo tiempo cómplice y contestatario de la situación actual, no lo haga caer en el peligro de convertirse en instrumento ideológico que haga caer que se puede hacer justicia sin cambiar la sociedad. (ILSA, 1989)

Assim, de acordo com Vladimir de Carvalho Luz (2008), em um dos um dos trabalhos de pesquisa mais destacados devido ao conteúdo e a amplitude, concentra-se na investigação apoiada pelo ILSA (realizada por Fernando Rojas Hurtado), de 1988, intitulado Comparación entre las tendências de los Servicio Legales em Noteamérica, Europa y América Latina, abordando as experiências de serviços legais nos países Chile, Equador, Colômbia e Peru. Constitui-se em importante pesquisa comparativa sobre serviços legais no continente, através do qual surgiu o termo serviços legais inovadores.

Tal pesquisa e demais trabalhos estão divulgados num importante veículo de crítica jurídica desenvolvido pelo instituto, a revista denominada El Otro Derecho, que desde sua primeira edição em 1989, segue até os dias atuais publicando textos de crítica jurídica sobre a realidade da região. Atualmente o instituto conta com um sítio na internet com vasta produção intelectual dos mais variados assuntos ligados a filosofia, sociologia, política, economia e claro, direito. ${ }^{6}$

Além de oferecer este rico aparato teórico, recorda A. C. Wolkmer, que, o ILSA não só tem privilegiado o estudo de culturas informais, como sobretudo, tem incentivado a formação de coordenações nacionais de práticas jurídicas insurgentes em toda a América Latina. (2015, p. 235) Vale lembrar também que aos dez anos do ILSA em sua reunião no ano de 1988, para avaliação do futuro do instituto, ficou convencionado que (...) El papel de ILSA es reflexionar, a cada paso, sobre la agenda crítica para la construcción de una regulación alternativa; aunar recursos, motivar a la autoreflexión de grupos de servicios legales, y atraves de ellos, a los grupos e las organizaciones populares. (ILSA, 1989)

\footnotetext{
${ }^{6}$ Para visitar o sítio do ILSA, acessar http://ilsa.org.co:81/
} 


\section{PARA UM PLURALISMO JURÍDICO DE TEOR COMUNITÁRIO-PARTICIPATIVO}

No encerramento do panorama contemporâneo, há que ressaltar a proposta de um pluralismo jurídico, enquanto produção teórico-prática desde o sul global e que poderá servir de embasamento ou referencial para as demais práticas normativas plurais no continente. Trata-se do pluralismo jurídico comunitário-participativo, desenvolvido por Antonio Carlos Wolkmer, professor e pesquisador dos cursos de Pós-graduação em Direito do Unilasalle-RS e da UFSC, o qual desenvolveu, no início da década de 1990, na sua tese de doutorado, Pluralismo Jurídico - Fundamentos de uma nova cultura no Direito, a questão da evolução e do declínio da cultura jurídica estatal moderna, explorando a crise de juridicidade e política do Estado contemporâneo, as incongruências da justiça no Brasil, e a forte consideração do que denomina as fontes de produção da nova cultura jurídica (os movimentos sociais como sujeitos coletivos).

Porém, o mais destacado fator de sua obra pode estar relacionado ao pluralismo jurídico como um marco de alteridade, verificado junto às práticas de justiça participativa no contexto de sociedades do capitalismo periférico, sobretudo no espaço geopolítico compreendido pela América Latina. Expressando a partir de forte erudição e profundo conhecimento históricocrítico, as perspectivas da teoria crítica do direito no continente e as manifestações insurgentes de juridicidade.

Em termos teóricos, verifica A. C. Wolkmer, que o pluralismo jurídico esta caracterizado (...) como a multiplicidade de práticas jurídicas existentes num mesmo espaço sócio-político, interagidas por conflitos e consensos, podendo ser ou não oficiais e tendo sua razão de ser nas necessidades existenciais, materiais e culturais. (WOLKMER, 2001, p. 219)

Nota-se, na obra do autor, a íntima relação da fonte plural do direito nascer das necessidades fundamentais, retoma-se assim a idéia já trabalhada acima por outros pesquisadores sobre os povos ou grupos sociais que criam suas normas para atender as necessidades de organização. Contudo para o pesquisador, tal necessidade se conforma em questões existenciais, materiais e culturais, fundadas em torno do sistema periférico capitalista pela de ausência de suprimentos para determinadas camadas, advindas de uma cultura de acumulação, pobreza e concentração de renda, somada a inexistência de um Estado de BemEstar; o que se pode verificar são variadas manifestações de produção jurídica ligadas a participação democrática e comunitária.

É destas múltiplas fontes comunitárias e experiências de juridicidade alternativa nas democracias em processo de descolonização, que A. C. Wolkmer irá fundamentar seu pluralismo jurídico comunitário participativo, oriundo da crise de afirmação da juridicidade 
monista neste espaço marginal da sociedade contemporânea. Assim,

\begin{abstract}
Afirma-se, deste modo, a proposta de um novo pluralismo jurídico (designado comunitário-participativo) configurado através de um espaço público aberto e compartilhado democraticamente, privilegiando a participação direta de agentes sociais na regulação de instituições-chave da sociedade e possibilitando que o processo histórico se encaminhe por vontade e sob o controle de bases comunitárias. (WOLKMER, 2001, p. 78)
\end{abstract}

Nesse sentido, é basilar o desenvolvimento epistemológico de uma nova proposta crítica de pluralismo jurídico assentada em cinco pilares que se articulam na dimensão "comunidade e participação": a) legitimação de novos sujeitos sociais; b) fundamentação na justa satisfação das necessidades humanas; c) democratização e descentralização do espaço público participativo; d) defesa pedagógica por ética da alteridade; e) consolidação de processos conducentes a uma racionalidade emancipatória ${ }^{7}$.

Expõem-se cada item, começando pela legitimação dos novos sujeitos sociais em contraposição ao sujeito coisificado, abstrato, privado e metafísico do liberalismo moderno coloca-se o caso dos movimentos sociais organizados em torno das lutas políticas no contexto de exigibilidade e atendimento as suas demandas sociais. Em seguida, impõe-se a exigibilidade política da satisfação das necessidades fundamentais, que são exigências por bens materiais e imateriais de sobrevivência, com dignidade.

Para isso necessita-se da democratização da esfera pública, ou seja, da reinvenção criadora do espaço público tradicional dominado por clientelismo, autoritarismo e instabilidade sociopolítica para uma cultura de participação popular intensa.

Outra característica é a defesa pedagógica em favor da ética da alteridade que, segundo A. C. Wolkmer $(2015$, p. 314), (...) é a ética antropológica da Solidariedade (...) comprometida com a dignidade do outro. Por último, a consolidação de processos conducentes a racionalidade emancipatória; ou seja, (...) racionalidade anti-tecno-formal, oposta a concepções operacionalista, calculista (...) voltada aos interesses históricos, da expressão de uma identidade cultural. (2015, p. 327)

\footnotetext{
${ }^{7}$ WOLKMER, Antonio Carlos. Pluralismo Jurídico: Fundamentos de uma nova cultura do direito. 4ed. São Paulo: Editora Saraiva, 2015, pp. 276-327.
} 
Evidencia-se um pluralismo jurídico de base comunitária, não se confundindo com o reconhecimento e impulso dado pelo pluralismo de Estado, aquele conformado em políticas públicas advinda da constatação de insuficiência de resposta por parte do Direito tradicional às complexidades sociais, na reformulação dos conceitos dentro da ótica liberal/individualista de matriz filosófica iluminista e burguesa que procura se adequar a nova realidade para seguir hegemônica, tal como ocorre nas políticas reformistas judiciais, em que os tribunais se lançam em programas assistencialistas de prestação jurisdicional voluntária e caritativa, minorando a carga de culpa de seus operadores, seja pela morosidade, seja pelo distanciamento histórico impetrado por seus antecessores.

Concluindo sobre a proposta do autor, importa mencionar que este atribui duas tipologias ao pluralismo jurídico: a) pluralismo jurídico conservador, matriz liberal individualista, indivíduos isolados, mobilizados em intentos privatistas econômicos, podendo lembrar-se aqui a manifestação de interesses de grandes conglomerados multinacionais e suas pressões capitalistas exclusivistas; b) pluralismo jurídico emancipatório, fundado em bases integradoras, que une indivíduos, sujeitos coletivos e grupos organizados em torno de necessidades comuns. (WOLKMER, 2008)

Ademais, relevante para os estudos sócio-jurídicos é a classificação que faz o autor quando distingue: a) Pluralismo Jurídico de Estado, modelo reconhecido, permitido e controlado pelo Estado, que diante da crise de insuficiência em atender as demandas e exigibilidades por justiça de seu direito engessado, abre-se em parte para recepcionar sob seu manto algumas manifestações alternativas de justiça; e b) Pluralismo Jurídico Comunitário, forças sociais e sujeitos coletivos com identidade e autonomia próprias, independente do controle estatal; manifestação de justiças comunitárias e suas práticas jurídicas autônomas e independentes da intervenção do Estado, onde manifesta-se um direito mais efetivo, concreto e vivo (WOLKMER, 2015).

\section{CONCLUSÃO}

Após o breve panorama de algumas ideias e perspectivas do pluralismo jurídico na América Latina, desde as investigações, teorias e manifestações na realidade prática, chegando a proposta do pluralismo jurídico comunitário-participativo e suas cinco características marcantes de refundação da cultura jurídica para o continente latino-americano, vale ressaltar que não se pretendeu recriar novos paradigmas doutrinários. A proposta levantada por cada uma das exposições presentes na teoria de base é justificada dentro de um projeto original de pensar a sociedade periférica em processo de descolonização, em que haja 
a ressignificação do direito dominante, culturalmente reproduzido e que não tem historicamente considerado as maiorias historicamente alijadas das esferas decisórias.

Certamente, as críticas e as posturas reflexivas ao marco teórico pluralista refletem a necessidade de inquietude política em relação aos fatos, às teorias, às práticas e mesmo às formas e mecanismos de manifestação, às vezes equivocadamente chamadas de justiça social.

Essa abertura teórica no campo jurídico possibilita a estruturação de aparatos contrahegemônicos, insurgentes, que problematizam as estruturas do direito hegemônico, expandido dentro de uma ideia de reinvenção solidária e participativa/comunitária do Estado e do Direito. Considera-se que este texto é uma introdução panorâmica do tema, que possibilita um mapeamento teórico do fenômeno.

Finalmente, após ter sido explorada outra ideia de direito e justiça, não mais calcada na individualidade, no formalismo ou na retórica da proibição e negação do Outro, resta reafirmar uma vertente de um direito plural, com sentido de alteridade, interculturalidade e racionalidade liberadora, esta entendida em sentido macro, ou seja, não mais refém das limitações jurídicas, sociais e econômicas que oprimem.

\section{REFERÊNCIAS}

CÁRCOVA. Carlos María. A opacidade do direito. Traduzido por Edilson Alkmin Cunha. São Paulo: LTr, 1998.

CORREAS, Oscar. Introducción a la Sociología Jurídica. México: Ediciones Coyoacán, 1994.

(coord.). Pluralismo Jurídico: otros horizontes. Ediciones Coyocán: DF, México. 2007.

(coord.). Derecho indígena mexicano, I e II. Ediciones Coyocán: DF, México. 2009.

LUZ, Vladimir de Carvalho. Assessoria Jurídica Popular no Brasil: Paradigmas, formação histórica e perspectivas. Rio de Janeiro: Editora Lumen Juris, 2008.

REVISTA EL OTRO DERECHO. Qué es ILSA, hacia dónde va?” In: El otro derecho. Bogotá: ILSA, n. 3, Jul./1989. p. 5-49. 
TORRE RANGEL, Jesús de la. Los Pobres y el uso del derecho. Em: RECH, Daniel; et al. Direito insurgente: o direito dos oprimidos. Rio de Janeiro: AJUP/Fase, out. 1990, p. 28-34.

. Pluralismo Jurídico enquanto fundamentação para a autonomía indígena. Em.

WOLKMER, Antonio Carlos. Direito Humanos e Filosofia Jurídica na América Latina. Rio de Janeiro: Lumen Juris, 2004.

Derecho y liberación: pluralismo jurídico y movimientos sociales. Bolivia: Editorial Verbo Divino, 2010.

Iusnaturalismo histórico analógico. México: Editorial Porrúa, 2011.

El derecho que nace del pueblo. México: Centro de investigaciones Regionales de Aguascalientes, 1986.

WOLKMER, Antonio Carlos. Pluralismo Jurídico: Fundamentos de uma nova cultura do direito. 3ed. São Paulo: Editora Alfa Omega, 2001.

Pluralismo Jurídico: Fundamentos de uma nova cultura do Direito. 4ed. Atualizada e ampliada. São Paulo: Ed. Saraiva, 2015.

Introdução ao Pensamento Jurídico Crítico. 6. ed. São Paulo: Saraiva, 2008. 